This is the peer reviewed version of Roberts, E.E., Lees J.M. and Hoult, N.A. (2012) "Flexural Fatigue Performance of CFRP Prestressed Concrete" Advances in Structural Engineering v.15, (4):575:588 which has been published on http://dx.doi.org/10.1260/1369-4332.15.4.575

\title{
Flexural Fatigue Performance of CFRP Prestressed Concrete Poles
}

\author{
E. E. Roberts ${ }^{1}$, J.M. Lees ${ }^{2}$ and N. A. Hoult ${ }^{3}$ \\ ${ }^{1}$ Graduate Structural Engineer, ARUP, 13 Fitzroy Street, London, UK, W1T 4BQ \\ ${ }^{2}$ University Senior Lecturer, Department of Engineering, University of Cambridge, Trumpington St., \\ Cambridge, UK, CB2 1PZ. \\ ${ }^{3}$ Assistant Professor, Department of Civil Engineering, Queen’s University, Ellis Hall, Kingston, Ontario, \\ Canada, K7L 3N6.
}

\begin{abstract}
Carbon Fibre Reinforced Polymer (CFRP) prestressed concrete poles offer a durable, light-weight alternative to conventional steel-reinforced or prestressed concrete poles. In particular, the corrosion resistance of the CFRP tendons can result in lower maintenance costs and a reduction in the required concrete cover. For lighting poles used in pedestrian or low-trafficked areas, wind loading represents a dominant load case. The wind acts as a transient force and can blow from any direction. It is therefore of interest to investigate how CFRP prestressed lighting poles perform under repeated cyclic loads and/or load reversals. Experiments were carried out on pole sections tested horizontally. These included a static control test and a conventional fatigue test where a cyclic load was applied in a downwards direction for 2 million cycles. Three further fatigue tests where the load direction changed, either after a defined number of cycles or within a load cycle, were also conducted. It was found that all the poles performed adequately for 1-2 million cycles of loading and that the majority of any deflection increases occurred within the first 50,000 cycles. It is believed that repeated cyclic loading may have increased the tendon debonding at the crack locations. Localised debonding potentially relieves the stress in the outermost tendon layer which delays the onset of failure and allows the inner tendon layers to take up further stress thus leading to a higher load carrying capacity. Loading orientation reversal from a downwards to an upwards direction within a loading cycle did not result in a greater stiffness degradation when compared to the other fatigue tests. The initial findings suggest that in-service cyclic loading and load reversals will not be detrimental to the performance of CFRP prestressed concrete poles.
\end{abstract}

KEYWORDS: CFRP; fatigue; concrete; prestressing; lighting pole. 


\section{INTRODUCTION}

There are 6.5 million lighting poles in the UK [1]. Roads represent an aggressive exposure environment and the susceptibility of steel to corrosion can lead to higher maintenance costs and ultimately limit the lifetime of steel, steel-reinforced or steelprestressed concrete lighting structures. One advantage of prestressing concrete with carbon fibre reinforced polymer (CFRP) tendons is that the tendons are durable resulting in structures with lower maintenance requirements and lifecycle costs. The corrosion resistance of CFRP also means that the concrete cover in the lighting poles can be reduced when compared with similar steel-reinforced concrete poles which leads to a reduction in the total weight. The first application of centrifugally cast concrete pylons with CFRP tendons was in a high voltage transmission line in the year 2000 [2].

The high strength concrete CFRP prestressed lighting poles tested in the current work were designed to meet the relevant European EN40 standards for use in lightly- trafficked or pedestrian areas [3]. During service the poles will be subjected to cyclic wind loads that may occur in any direction. Although the poles are designed to be fully prestressed in service, exceptional wind loading, or accidental damage due to impact, may result in the poles becoming cracked so it is important that the fatigue behaviour of these poles in the cracked state is investigated. Of particular interest is the combined prestressed concrete/tendon system performance under repeated loads.

\section{FATIGUE BEHAVIOUR}

Fatigue damage is caused in a material or in a structure that undergoes fluctuating loads that are less than the static failure load. This damage is irreversible and may result in a decrease in strength and stiffness, increased cracking, and ultimately catastrophic failure. Normal strength concrete does not have a fatigue limit, so fatigue damage begins to occur even at low stress ranges. Microcracks in the concrete occur first at the interface between the mortar and the aggregate and then propagate into the mortar [4]. As fatigue failure 
approaches there is extensive cracking at aggregate interfaces which increases hysteresis and non-elastic strain, hence reducing the secant modulus of elasticity [5]. The high strength concrete used in the poles has a lower and smaller aggregate content so cracking may start in the mortar and propagate more rapidly, lowering the fatigue life [6].

In steel-reinforced concrete, the fatigue capacity of high strength reinforced concrete has been found to depend on the bond interaction between the concrete and deformed reinforcement rather than on any individual strength property [4]. Work on steelprestressed concrete, cited in [7], has shown that the tendon fatigue life in beams is shorter than that measured for the bare tendons in air. These results highlight the need to consider both the constituent materials and the prestressed concrete system when assessing the fatigue performance.

Any FRP tendon degradation will be related to the fibre arrangement and volume fraction, since for high volume fractions viscoelastic flow occurs preferentially between the closely spaced fibres and can lead to the initiation of debonding at the matrix-fibre interface [8]. Damage often occurs over a large volume of the material, leading to a decrease in the modulus of elasticity, a more pronounced hysteresis loop, and a decrease in the residual strength of the material [9]. While the fatigue resistance will depend on the details of the CFRP product and the load cycling, carbon fibres and epoxy resins are generally known for their good fatigue resistance, as illustrated by the representative S-N curve for CFRP tendons shown in Figure 1. Work by Uomoto et al [10] on the fatigue performance of bare CFRP rods has shown that even with a mean stress of $1100 \mathrm{MPa}$ (where the static strength of the CFRP rod was $1390 \mathrm{MPa}$ ) and a stress amplitude of 100 $\mathrm{MPa}$, the measured resistance was greater than four million cycles.

With CFRP-prestressed concrete, although the tendon fatigue resistance is expected to be good, the overall pole behaviour will be a reflection of the FRP surface profile and the resulting bond between the concrete and the CFRP prestressed reinforcement. However, the surface profiles of FRP tendons differ. Sand coated, braided, twisted, smooth or profiled rods, where the profile is either formed in the outer layer of resin rich epoxy or 
with additional fibre wrapping, have been proposed [11]. Even within each of these categories there can be significant differences in the bond behaviour. An SEM image [12] of the sand-coated tendons used in the current work exemplifies this complexity (see Figure 2(a)) where the bond will be a function of the chemical adhesion, friction and mechanical interlock between the core tendon, the sand coating and the concrete. The deterioration of any of these mechanisms due to repeated loading will result in changes in the structural system performance.

The fatigue resistance of the FRP tensile reinforcement may also be lowered by any rubbing between the concrete and the tendon at crack locations which may cause damage to the surface of the tendon hence reducing the capacity. Rahman et al. [13] have shown that there was a reduction in the fatigue strength of CFRP rods embedded in concrete when compared with CFRP rods tested in isolation. However, fatigue studies on pretensioned CFRP prestressed concrete beams have indicated that there appear to be no significant strength reductions due to fatigue cycling [14-16].

\section{EXPERIMENTAL DETAILS}

The original centrifugally cast CFRP lighting poles were $9.2 \mathrm{~m}$ long with a cylindrical section that tapered from the largest outside diameter of $212 \mathrm{~mm}$ at the base to the smallest outside diameter of $120 \mathrm{~mm}$ at the pole tip (see Figure 2). An experimental investigation, where five poles were tested as cantilevers to determine the influence of a fuse box opening, has been reported elsewhere [3]. At the end of that testing programme, a length of approximately 3-4 m was cut from the top of each of the five poles. This zone did not exhibit any visible cracking although it is possible that some damage was present as a result of the original tests. The experiments reported here were conducted on these five cut samples.

\subsection{Concrete Properties}


The high strength concrete (HSC) contained rapid hardening cement and silica-fume to provide high early strength. Concrete cube and cylinder control tests were carried out after 28 days and the average ultimate compressive $150 \mathrm{~mm}$ cube strength across the five poles was found to be $105 \mathrm{MPa}$. The average Young's modulus of the HSC was 38,550 MPa. In the earlier cantilever tests the concrete tensile strength was back calculated to be between 5.1 MPa and 7 MPa. As the poles were approximately six years old at time of testing, the Eurocode 2 method [17] was used to reflect the time-dependent strength gain. The compressive strength at six years would be expected to be around $20 \%$ stronger than that measured at 28 days and so was taken as $125 \mathrm{MPa}$. The associated increase in stiffness would be about 7\% and so the Young's modulus was taken as 41,500 MPa.

\subsection{CFRP Properties}

Tenax UTS type 5613 pultruded uni-directional tendons were used to reinforce the poles. The tendons consist of 68\% unidirectional carbon fibres in a bakelite epoxy matrix, and have a ceramic coating as shown in Figure 2(a) to improve their bond performance. The tendons had a nominal diameter of $4 \mathrm{~mm}$ and a coated diameter of $4.6 \mathrm{~mm}$. The manufacturer's mean ultimate tensile strength of the tendons was 2292MPa with a standard deviation of $96 \mathrm{MPa}$ and the mean longitudinal tensile modulus of elasticity was 161,000 MPa with a standard deviation of 1,000 MPa. However, as can be the case with tensile tests on CFRP tendons, premature failures can occur in the anchorages which influence the measured results. The initial prestress in each tendon before losses was $58 \%$ of the ultimate strength (1330 MPa). The prestress in the tendons reduced to 1100 MPa after losses due to elastic shortening, concrete creep and tendon relaxation. Further details of tendon tests and concrete properties can be found in [18].

\subsection{Test Specimens}

The CFRP prestressed concrete pole specimens were produced in Switzerland by SACAC AG in 2002 using high strength concrete and centrifugal casting methods to give a hollow circular cross section. The wall thickness of the concrete was constant at $40 \mathrm{~mm}$ but the 
$10 \mathrm{~mm} / \mathrm{m}$ taper of the poles resulted in a changing diameter along the length (the outside diameter varied between $127.5 \mathrm{~mm}$ and $151.5 \mathrm{~mm}$ for the specimens in this study). The concrete cover to the tendons was $18 \mathrm{~mm}$. The section was prestressed using six CFRP tendons. A schematic diagram of a typical pole cross section is shown in Figure 2(a). There was no additional reinforcement in the length tested with the exception of one pole, denoted as ST1 in the following, which had additional spiral CFRP tape reinforcement (see Figure 2(b)) [18]. The thin, $0.14 \mathrm{~mm} \times 13 \mathrm{~mm}$, tape was wound around the outside of the longitudinal tendons at a pitch of $35 \mathrm{~mm}$ prior to casting.

\subsection{Design of testing parameters}

Since the specimens were cut from actual lighting poles, the geometry, prestressing tendon layout and material properties were fixed. Furthermore, the aim of the current work was not to recreate the natural frequency of an actual lighting pole but instead to mimic the tendon stress conditions at a crack to determine if any local bond or tendon deterioration would occur. To better assess the load versus deflection relationship, the poles were tested horizontally as simply supported beams rather than as vertical cantilevers. A contributing factor in this decision was that, unless additional end blocks were cast, a fixed end-condition could not be adequately created with the existing pole sections. Furthermore, a simply supported beam test of length $L$ is equivalent to two cantilever beam tests of length $L / 2$ where the line of symmetry at the centre of the beam in the simply supported test is equivalent to the fixed end condition in a cantilever test in terms of moments and rotation conditions. In the current work, due to the taper of the pole, the pole is not symmetrical about midspan but this was nevertheless deemed to be an acceptable trade-off in order to simplify the test procedures.

The poles were tested in three point loading. The three point bending test is equivalent to a point load being applied to the tip of a cantilever. This would be more analogous to the resultant force due to the wind loading on the lantern rather than due to a uniformly distributed load (UDL) being applied along the length of the pole, which would be more representative of the wind loading along the pole. However, as the deflection under a 
point load is greater than the deflection under an equivalent UDL, this is a conservative approach. The span and loading arrangements were selected based on a sectional analysis of the critical cross-section to ensure that the ultimate failure would be due to tendon rupture. This would enable the assessment of the residual tendon capacity. The applied cyclic load range was chosen to reflect a stress range of between $47-60 \%$ of the ultimate stress in the extreme CFRP tendon. This represented the upper limit of what the pole would be subjected to during its lifetime and included both the decompression and cracking loads.

The typical loading frequency that the poles would experience in service due to wind loading is likely to be less than $1 \mathrm{~Hz}$. However, due to the time constraints, such a low rate of loading was not feasible. Work by Raithby and Whiffen [19] suggests that there is no difference in the fatigue life of concrete for frequencies between $0.5 \mathrm{~Hz}$ and $7.5 \mathrm{~Hz}$. A frequency of $5 \mathrm{~Hz}$ was chosen to balance testing time constraints with the need to ensure that the selected frequency was less than that which might induce undesirable heating in the CFRP tendon [20] and/or resonance in the pole.

The number of cycles was also selected to balance the length of testing and the need to ensure that the fatigue performance was sufficiently evaluated. The total number of load cycles was taken as 2 million since it has been estimated [21] that structures do not undergo more than this many load repetitions during their lifetime.

\subsection{Test Procedure}

The poles were tested in three point bending with a span between supports of $2.4 \mathrm{~m}$ (see Figure 3). Since the pole was tapered, the moment resistance varied along the length of the pole so there was not felt to be a particular advantage in conducting four point bending tests. The tendon orientation was as shown in Figure 2(a) and was kept the same for each test. The poles were aligned so that the outer diameter at mid-span was $139.5 \mathrm{~mm}$. Due to the taper, the outer diameters at each support were then $127.5 \mathrm{~mm}$ and $151.5 \mathrm{~mm}$ respectively. The minimum overhang length measured from the centre of the 
support at either end the pole was $120 \mathrm{~mm}$. The transfer length for similar tendons with an initial prestress of $1000 \mathrm{MPa}$ has been found elsewhere to be around $70 \mathrm{~mm}$ [3].

One pole was tested statically until failure (ST1). Two poles were tested under cyclic loading for a total of 2 million cycles at $5 \mathrm{~Hz}$ (FT1 and FT2) and then tested statically until failure. However, whereas fatigue test 1 (FT1) involved 2 million load cycles in a single downwards direction, fatigue test 2 (FT2) consisted of 1 million downwards load cycles (FT2-1) followed by another 1 million downwards cycles after the pole had been rotated by $180^{\circ}$ (FT2-2). The applied cyclic load range of +1 to $+8 \mathrm{kN}$ for FT1 and FT2 induced the desired stress range of $47-60 \%$ of the ultimate stress in the extreme tendon. A further two poles were tested where the load was applied downwards and then upwards within a cycle for a total of 1 million cycles (FT3 and FT4) and then tested statically to failure. For FT3 and FT4 a load range of -8 to $+8 \mathrm{kN}$ was used and the cycling frequency reduced to $2.5 \mathrm{~Hz}$ so that the frequency of the half cycle $(0$ to $+8 \mathrm{kN})$ was roughly comparable to FT1 and FT2. The test programme is summarised in Table 1.

With the aim of establishing a common baseline, FT1, FT2-1, FT2-2, FT3 and FT4 were all preconditioned by conducting three static loading and unloading tests up to the maximum cyclic load prior to the commencement of the fatigue testing. By conducting three static loading cycles it was also possible to observe changes in stiffness and cracking of the specimens in greater detail. In the fatigue tests, the cyclic load was applied using an AMSLER Hydraulic Pulsator attached to a hydraulic jack mounted on a test rig as shown schematically in Figure 3. The pole was supported on roller end supports connected to pedestals that were bolted to the floor. The load was applied via a calibrated load cell, restraining cup, plate, and collar. The test rig was modified for FT3 and FT4 to incorporate two springs, a jack, and a load cell below the pole to provide the restoring force required for through-zero loading. This arrangement is shown in Figure 4(a) and was used since the jacks available were designed only to act in a single downwards direction. To accommodate the upward loading, the end supports had to be modified using two springs and an extra collar at each pedestal as shown in Figure 4(b). This support configuration was intended to provide vertical restraint at each support 
whilst allowing free rotation and horizontal movement. A load cell was placed between the upper jack and the pole and a second load cell was placed between the lower jack and the pole. The end support springs were initially prestressed to a load of $4.5 \mathrm{kN}$. An initial upwards load of $9 \mathrm{kN}$ was then applied through a load cell by the bottom jack supported on springs. The restoring force was applied using the pulsator jack on the top face. At the equilibrium point (where the beam deflection was zero), the measured forces in both jacks were found to be $9.8 \mathrm{kN}$. At this point, the force in the springs consisted of the initial upwards load plus a small additional force component required to bring the beam deflection back to zero. A cycling range of between $1 \mathrm{kN}$ and approximately $18.5 \mathrm{kN}$ in the pulsator jack was therefore required to achieve the required load range of -8 to $+8 \mathrm{kN}$.

\subsection{Data Capture}

In all of the tests, the deflection was measured using five Linear Resistance Displacement Transducers (LRDTs) spaced at $0.4 \mathrm{~m}$ intervals along the pole as shown in Figure 3. The deflection measurements were logged to a computer using a high speed data logger. During the fatigue tests, readings were taken during the first $8 \mathrm{~s}$ of every hour at a capture rate of $100 \mathrm{~Hz}$, giving 20 data points in each of the 40 stress cycles recorded. The dynamic results were analysed to obtain the changes in stiffness and deflection at the centre of the pole during the test.

\section{RESULTS AND DISCUSSION}

It was found that the lighting pole sections performed well under fatigue loading since none of the poles failed during cycling. In the following, the initial static testing, the behaviour during the cyclic tests and the post-fatigued static tests to failure are discussed.

\subsection{Initial loading results}

The initial behaviour observed in the static load test ST1 and the first static load cycle of specimens FT1-FT4 are comparable across all five poles. The theoretical cracking load 
would be expected to be between 5 and $6 \mathrm{kN}$, allowing for the variations in the measured concrete tensile strengths. Cracking occurred in all the specimens during the initial loading, in some cases at loads less than the theoretical values. Experimental deflection profiles for $4 \mathrm{kN}$ and $7 \mathrm{kN}$, which represent loads below and above the theoretical cracking load respectively, are shown in Figure 5. The predicted deflections using an uncracked section analysis have also been included in the figure. It can be seen that at 4 $\mathrm{kN}$ the difference between the largest (ST1) and smallest (FT4) mid-span deflection is approximately $13 \%$. This variation could be attributed to a combination of factors including experimental influences (the displacements at this load are fairly small) and differences in concrete stiffness. The pole geometry may play a role but as the outer perimeter of a pole is fixed by the formwork, any difference in pole thickness will have a relatively small impact on the gross second moment of area. Even though visible cracking had been observed, the deflections were slightly less than predicted using an uncracked elastic analysis which could suggest that the concrete was stiffer than anticipated. Or a further factor could be that during the initial loading the cracking was limited to the extent that the behaviour was still primarily dominated by the uncracked section properties. At $7 \mathrm{kN}$, the deflection of ST1 is much higher than the other poles. Possible reasons for the lower stiffness of ST1 at loads above the theoretical cracking load are discussed in later sections. The difference between the mid-span deflections of FT1 to FT4 is approximately 12\%. Again, even though the poles had cracked, these deflections remain slightly below those calculated using the uncracked sectional analysis. After the three static load and unload cycles for FT1-FT4, the residual displacements at mid-span were typically between 0.2 and $0.3 \mathrm{~mm}$.

\subsection{Load cycling}

One issue in all the cycled specimens is that because of differences in the residual displacements after the static load/unload cycles and, in the case of FT2, the need to rotate the beam after test 1 , the baseline 'zero' deflections differ between the tests. However, since these residual differences were small, for simplicity, in all the loadcycling results the 'zero' was taken as the deflection at the start of cycling at zero load. It 
is of note that around 500 to 1000 cycles were necessary to reach the required load levels and for the load cycling to stabilise due to the nature of the testing equipment. This is because the loading system was displacement controlled. In the early stages of testing the specimen stiffness decreased resulting in larger displacements for a given load. Thus to keep the load range constant the amount of displacement was increased, which required constant adjustment over the first 500 to 1000 cycles. However, the fatigue stress in the tendons was not exceeded during this time and the load range was kept as close as possible to the required load range until the displacements stabilized and so this was not believed to have a significant effect on the fatigue behaviour. A further distinction is that, for a given load, the displacement can be measured on either the ascending or the descending part of the load cycle. Due to dynamic effects and load recovery there was some noise in the displacement readings at the minimum and maximum load values. In the following discussion, ascending values have been used and the behaviour at a load value of $7 \mathrm{kN}$ was considered to be more reliable than the measured displacements at the peak load of $8 \mathrm{kN}$. At an applied load of $7 \mathrm{kN}$, the theoretical neutral axis depth assuming a cracked elastic sectional analysis is approximately $60 \mathrm{~mm}$ from the top of the section.

There were problems with the data capture during periods of the fatiguing of FT1 so these results have not been reported here. However, the change in deflections obtained from the dynamic data during the cycling of FT2 (Tests 1 and 2) at loads of 4 and $7 \mathrm{kN}$ have been compared in Figure 6(a). Again there were data capture problems in FT2-1 after around 700,000 cycles so the measured deflections beyond this point are not available. For comparison, the measured deflection during the third static load/unload cycle conducted prior to the commencement of the fatigue tests for both test 1 (1.62 $\mathrm{mm}$ at 4 $\mathrm{kN}$ and 3.01 at $7 \mathrm{kN})$ and test $2(1.39 \mathrm{~mm}$ at $4 \mathrm{kN}$ and $2.99 \mathrm{~mm}$ at $7 \mathrm{kN})$ are also indicated in the figure. It was observed that after 1 million cycles at a load of $4 \mathrm{kN}$, the deflection increase when compared to the static load/unload result was around $0.4 \mathrm{~mm}$ for FT2-1 and approximately $0.5 \mathrm{~mm}$ for FT2-2. At $7 \mathrm{kN}$, the increase in FT2-1 of $0.6 \mathrm{~mm}$ was similar to that of FT2-2 which was approximately $0.7 \mathrm{~mm}$. In both tests, between $68-88 \%$ of the deflection increases occurred within the first 50,000 cycles. This suggests that at this point a stable crack pattern has developed. This trend can also be seen in 
Figure 6(b) where the load versus deflection behaviour for FT2-1 at selected numbers of cycles has been plotted.

FT3 and FT4 were nominally identical tests except that, due to measurement problems, FT3 was inadvertently loaded between $-8 \mathrm{kN}$ and $+6 \mathrm{kN}$ rather than the desired $-8 \mathrm{kN}$ to $+8 \mathrm{kN}$ achieved in FT4. The deflection with increasing cycles at upwards and downwards loads of $4 \mathrm{kN}$ and $7 \mathrm{kN}$ respectively for FT4 can be found in Figure 7. The pre-fatiguing static load/unload cycles were only conducted in the downwards direction and the deflection values from the third static load/unload cycle have also been indicated in the figure. The deflection increases, when compared with the static deflection, were around $0.5 \mathrm{~mm}$ at $4 \mathrm{kN}$ and $0.6 \mathrm{~mm}$ at $7 \mathrm{kN}$ for FT4. For FT3, the deflections at $4 \mathrm{kN}$ in both directions and at an upwards load of $7 \mathrm{kN}$ are indicated. Results for a downwards load of $7 \mathrm{kN}$ for FT3 are not possible since, as discussed, this specimen was only loaded between $-8 \mathrm{kN}$ and $+6 \mathrm{kN}$. Furthermore, the downward values for FT3 relative to the static values appeared to be in error since the measured downwards deflections were less than those obtained in the static load/unload loop. For both the upwards and downwards loadings the majority of the changes in stiffness were observed in the first 50,000 cycles and, if anything, the displacement increases stabilized more rapidly in the FT3 and FT4 tests. After fatiguing, the residual mid-span displacements were between 0.4-0.5 mm. The overall cycling behaviour and stiffness changes in FT3 and FT4 were broadly similar to FT1, FT2-1 and FT2-2 suggesting the reversal of load direction did not have a significant influence on the results.

\subsection{Static load tests to failure and failure mechanisms}

Since none of the poles failed during cyclic loading, the poles were all tested to failure after cycling and the resulting experimental load displacement plots for FT1, FT2, FT3 and FT4 and the pole tested statically, ST1, are shown in Figure 8. In addition, after the tests had been completed, the critical sections were broken open to give an indication of possible failure mechanisms (see Figure 9). 
ST1 reached a maximum ultimate load capacity of $14.7 \mathrm{kN}$ whereas the ultimate failure loads of poles FT1, FT2, FT3 and FT4 were 8.5\%, 12.8\%, 8.9\% and 19\% higher than that of ST1 respectively. The deflections at failure were also higher for poles FT1, FT2 and FT4 whereas for FT3 the deflection at failure was lower than that in the static test. The experimental plots also illustrate the differences in the failure sequences. In ST1, it appeared that the first tendon failed at the peak load. The load dropped off but then increased again from a lower load level until the next two tendons failed at approximately $12 \mathrm{kN}$. In contrast, once the maximum load was reached, FT1 and FT2 cracked suddenly into two sections. This appears to be the result of the simultaneous tensile failure of the bottom three tendons, and failure of the top three tendons as the concrete failed (this can be seen in the photos shown in Figures 9(a) and 9(b)).

FT3 and FT4 seemed to fail progressively and loud noises were heard when drops in the load occurred between 13 and $14 \mathrm{kN}$ (as circled in Figure 8). In both poles, an extensive longitudinal crack appeared slightly above the mid-depth of the poles in the region of the central load at failure (see Figure 9(c)). In FT3 after failure, the beam returned to a relatively un-deflected shape, so was then reloaded until a further tendon failure occurred at $4 \mathrm{kN}$. Inspection of the broken pole FT3 (as shown in Figure 9(d)) showed that the bottom three tendons had snapped and that the top three were damaged. It could be observed that the tendon coating had broken down in the bottom three tendons and that debonding had occurred. Tendon debonding and/or local fibre breakage in the tendon could also account for the noises heard during the testing of FT3 and FT4 at a load of about $14 \mathrm{kN}$.

The results suggest that the tendons in FT1, FT2, FT3 and FT4 may have become debonded from the concrete at the critical crack locations, so the strain is averaged along the debonded length of the three bottom tendons. This type of behaviour will be investigated further in the next section.

One contradiction is that although the deflections of the control specimen ST1 were higher than that of the fatigued specimens at a given load, the failure load was lower. 
However the presence of the tape spiral in ST1 (see Figure 2(b)) makes direct comparisons difficult since in the regions where the spiral is in contact with the tendon there will be a local reduction in the tendon/concrete bond and the spiral will interact with the concrete in the compression zone.

\subsection{Moment curvature predictions from a sectional analysis}

A plane-sections-remain-plane sectional analysis was carried out to predict the failure load of the pole. In the analysis, the concrete model used [22] was

$\sigma_{c}=f_{c u}-f_{c u}\left(1-\frac{\varepsilon}{\varepsilon_{c u}}\right)^{\text {nheld }} \quad$ where nheld $=\frac{E_{c o} \varepsilon_{c u}}{f_{c u}}$

and $\sigma_{c}$ is the concrete stress associated with a concrete strain of $\varepsilon, f_{c u}$ is the ultimate flexural compressive strength, $\varepsilon_{c u}$ is the ultimate strain and $E_{c o}$ is the Young's modulus of elasticity. This expression has been found to be appropriate [23] for high strength concrete. The ultimate concrete strain in uniaxial compression is typically around 0.0035. However, due to the circular pole geometry and the high level of compaction which is achieved as a result of the spinning process, ultimate flexural concrete strains in $100 \mathrm{~mm}$ diameter poles with high strength centrifugally cast concrete (similar to that used in the current work) have been found to be greater than 0.005 and as high as 0.0069 [23]. An $\varepsilon_{c u}=0.0045$ was used in the predictions presented here to reflect a conservative estimate of the ultimate flexural concrete strain. It is of note that the dependency of the shape of the concrete model on the ultimate strain is primarily noticeable at higher stress levels and the ultimate strain will dictate the prediction of when concrete failure occurs. However, in the current work, the dominant failure mode was tendon failure. The CFRP tendons were assumed to be linear elastic. Because the section is symmetrically prestressed, in the unloaded state, the tendons exert a uniform stress. 
Due to the circular geometry, the cross-section was approximated as a series of thin rectangular strips of varying width. The analysis was programmed in MATLAB. The initial prestrain in the tendons was approximately $0.69 \%$ and this prestrain acts to apply a uniform compression to the pole. Under flexural loading, the baseline case used a perfect bond assumption, where the change in strain in the outer tendon due to flexure, $\varepsilon_{t o}$, is the same as that in the concrete at the same level, $\varepsilon_{c o}$. The average material properties used in the calculations were the same as those presented in the section on experimental details. These assumptions would result in the curvature profile shown in Figure 10(a) and the section failing due to the rupture of the outermost tendon at a load of $13.3 \mathrm{kN}$, a value which is significantly lower than the experimental failure loads. Two possible reasons why the experimental results are higher could be material variability or that, as a result of fatiguing, debonding occurred in the outer tendon at the critical section thereby reducing the stress in the outer-most tendon and enabling the next tendon layer to sustain higher loads.

The range of different failure loads that might be expected due to variability in the material properties was initially investigated. If concrete creep and/or damage occurred during cycling, the effective Young's modulus of concrete could reduce. However, for the poles tested here, the anticipated level of creep or damage was expected to be fairly small since the poles were approximately six years old at the time of loading, the maximum stress in the concrete during fatiguing was low (approximately $0.35 f_{c u}$ at the extreme fibre) and the fatigue cycling occurred over a short time-frame. However, there will be some variation between the concrete stiffness for each of the different poles since, although the same concrete mix was used, the poles were cast from different batches of concrete. If the tendon strength was higher than anticipated this will not change the stiffness of the cross-section but would act to increase the ultimate moment capacity of the cross-section. An example where the tendon failure strength was assumed to be $15 \%$ higher than expected is shown in Figure 10(b) and would result in an increased failure load of $15.2 \mathrm{kN}$. This is slightly greater than the observed failure load of ST1 (14.7 kN) but lower than that of FT1-FT4 which failed at loads between 16 and $17.5 \mathrm{kN}$. Considering that anchorage failure may result in lower tensile strengths being obtained 
and published by manufacturers, and making allowances for possible standard deviations, a $15 \%$ tendon strength increase is plausible.

It is of note that the original $9 \mathrm{~m}$ lighting poles [3] were tested in accordance with the European standard for lighting columns (EN40) and were found to meet the serviceability, structural and minimum ultimate load requirements for bending/torsion. As these tests were conducted on poles with fuse box openings where the tendons were deviated locally, aspects of the failure modes are not directly comparable. However, for cases where the tendon(s) failed, some variability in the tendon strength was noted and would be consistent with the sensitivity study presented here.

The possibility of debonding was also considered. For the pole orientation tested, the outermost tendon is the most highly stressed and thus it would be most likely to debond during fatigue cycling. Debonding would mean that the change in strain in the tendon due to flexure, $\varepsilon_{t o}$, is no longer the same as that in the concrete at the same level, $\varepsilon_{c o}$. Two possible scenarios are shown in Figure 10(c) and (d). In the first case (Figure 10(c)), debonding of the outermost tendon in tension occurs up to the point where the flexural strain in the outer tendon $\varepsilon_{t o}$ is the same as that of the next tendon layer, $\varepsilon_{t i}$. This would result in higher curvatures and a load capacity at failure of $14.8 \mathrm{kN}$. In the second case (Figure 10(d)), the combined effects of debonding of the outer tendon to a strain level equivalent to the next tendon layer and a tendon strength that was $15 \%$ higher than the manufacturer's value are considered. For this particular combination, the predicted failure load would increase to $17.0 \mathrm{kN}$.

For a given tendon strength (e.g. Figures 10(a) versus (c) or Figures 10(b) versus (d)) the debonding of the outermost tendon in flexural tension acts to reduce the stiffness of the cross-section and increase the ultimate failure load. This debonding then leads to higher strains in the next layer of tendons at failure but, as these tendons have reserve capacity, results in a greater efficiency since the strain in the outer tendon is relieved while the inner tendons can take up more force. There also needs to be sufficient strain capacity in the concrete to accommodate these greater curvatures. Steps in the experimental load- 
deflection curves could be an indication of localised debonding since a greater deflection for a given load would be expected. The overall impact on the deflection behaviour would depend on the crack pattern and the extent of debonding. It is therefore proposed that the combination of some tendon debonding during fatiguing combined with the tendons being stronger than anticipated could lead to the increased failure loads evident in Figure 8. However it is not possible to isolate the exact proportions of each of these two effects.

In terms of the implications on the overall deflection, a further distinction to be noted is the difference between local and global effects. Localised debonding at a highly stressed cracked cross-section as a result of fatigue cycles will increase the rotation at that particular crack but will not necessarily impact other regions away from this zone. In contrast, the lower stiffness of ST1 seems to be the consequence of global effects which are integrated along the length of the pole and which result in increased deflections even at relatively low load levels. As a result, it is believed that the presence of the tape spiral is somehow influencing the overall pole behavior. For example, in ST1 the relatively low pitch of the tape (35mm) and its proximity to the tendons potentially caused a reduction of the bond along the full length of the specimen, which would result in higher deflections. This would then have a greater impact on the global behaviour than the potential localised debonding at midspan in the fatigue specimens discussed previously. As such, the load-deflection behavior of ST1 should not really be treated as a static control specimen for comparison with FT1-FT4.

The small number of specimens tested in this experimental programme means that it is hard to draw firm conclusions. Nevertheless, the indications are that the fatigue performance of the pole sections was good and that the debonding of the outer tendon and the presence of layers of tendons may have allowed for load transfer from the most highly stressed tendon to the next tendon layer. The extent of the load transfer will depend on the number of tendon layers, the tendon orientation and the level of debonding. Further testing is required in order to support the initial results obtained in this investigation. 


\section{CONCLUSIONS}

An investigation of the fatigue performance and the effect of load reversals on CFRP prestressed concrete lighting pole sections was undertaken. The fatigue performance of the CFRP prestressed poles under stress ranges of $47-60 \%$ of the tendon ultimate strength in the outermost tendons was found to be satisfactory as none of the poles tested in fatigue failed after 1-2 million cycles of loading. The deflections during the fatigue tests were found to increase with the number of cycles but most of this increase occurred within the first 50,000 cycles. The downwards and upwards reversal of load direction in each cycle did not significantly change the overall behavior when compared with a solely downwards loading. It is believed that fatigue loading may increase the tendon debonding at the crack locations and relieve the stress in the outermost tendon thereby leading to a higher load carrying capacity. As such, the initial findings suggest that inservice load reversals will not be detrimental to the performance of the CFRP prestressed concrete lighting pole sections.

\section{ACKNOWLEDGEMENTS}

The authors would like to thank SACAC Ltd, Dr Giovanni Terrasi from EMPA and Mr. Martin Touhey and Mr. Simon Holder from Cambridge University for their help and support with this work.

\section{REFERENCES}

[1] Structural Safety, Review and Recommendations (1999). 12th Report of the Standing Committee on Structural Safety, SCOSS, London, 1999.

[2] Terrasi G., Battig, G. and Bronnimann, R. (2001). "Pylons Made of HighStrength Spun Concrete and Prestressed with CFRP for High Power Transmission Lines", Procs Fibre Reinforced Polymer Reinforcement for Reinforced Concrete Structures FRPRCS-5, V. 2, Thomas Telford, pp. 1103-1112. 
[3] Terrasi, G.P. and Lees, J.M. (2003). "CFRP Prestressed Concrete Lighting Columns", Field Applications of FRP Reinforcement: Case Studies, Eds S.H. Rizkalla and A. Nanni, American Concrete Institute International, SP-215, pp. 5574.

[4] Mor, A., Gerwick, B. C. and Hester, W. T. (1992). "Fatigue of High-Strength Reinforced Concrete", ACI Materials Journal, V. 89, No. 2, pp. 197-207.

[5] Neville, A. and Brookes, J. (1987). Concrete Technology, Longman, Essex, UK.

[6] Kim, J-K. and Kim, Y-Y. (1996). "Experimental Study of the Fatigue Behavior of High Strength Concrete" Cement and Concrete Research, V. 26, No. 10, pp 15131523.

[7] Collins, M. and Mitchell, D. (1987). Prestressed Concrete Basics, Canadian Prestressed Concrete Institute, Canada.

[8] Hull, D. and Clyne, T.W. (1995). Introduction to Composite Materials, Cambridge University Press, UK.

[9] Scholte, H.G. (1994). "Fatigue Characteristics", Composite Materials in Maritime Structures Volume 2 (Practical Considerations), Cambridge University Press, pp. 178-196.

[10] Uomoto, T., Nishimura, T. and Ohga, H. (1995). "Static and Fatigue Strength of FRP rods for Concrete Reinforcement" Procs Second International Symposium on Non-Metallic (FRP) Reinforcement for Concrete Structures, Ed. L. Taerwe, pp. 100-107.

[11] Manfredi, G., Realfonzo, R. and Cosenza, E. (1998). "FRP Bond to Concrete", in COST C1, State-of-the-art Review on Design, Testing, Analysis and Applications of Polymeric Composite Connections, EUR 18172 EN, Eds T. Mottram and G.J. Turvey, European Commission: Brussels. pp. 78-92.

[12] Scott, P. (2009). Aspects of CFRP Prestressed Concrete Durability in the Marine Environment, PhD Thesis, University of Cambridge, UK.

[13] Rahman A., Adimi M.R. and Benmokrane B. (1996). "Fatigue Behaviour of FRP Reinforcements Encased in Concrete". Procs of Second International Conference on Advanced Composite Material in Bridges and Structures, Quebec, Canada, pp. 691-698. 
[14] Nishikawa, K., Nakai, H., Mikami, H., Okano, M., Hamazaki, K. and Andou, S. (1993). "Dynamic Properties of Prestressed Concrete Beams using Various FRP Tendons", FIP Symposium on Modern Prestressing Techniques, Prestressed Concrete Engineering Association, Tokyo, Japan pp. 695-702.

[15] Abdelrahman, A.A., Tadros, G. and Rizkalla, S.H. (1995). "Test Model for the First Canadian Smart Highway Bridge", ACI Structural Journal, V. 92, No 4, pp. 451-458.

[16] Mertol, H.C., Rizkalla, S., Scott, P., Lees, J.M. and El-Hacha, R. (2006). "Durability of Concrete Beams Prestressed with CFRP". Case Histories and Use of FRP for Prestressing Applications, ACI Special Publication SP245-1, Eds R. El-Hacha and S.H. Rizkalla.

[17] BS EN 1992-1-1:2004 (2004). Eurocode 2: Design of Concrete Structures. General Rules and Rules for Buildings, BSI.

[18] Terrasi G.P. and Lees, J.M. (2006). CFRP Prestressed Concrete Lighting Columns: Experimental Bending/Torsion Behaviour, CUED/D-Struct/TR.212., Cambridge University Engineering Department, Cambridge, UK.

[19] Raithby, K. D., Whiffen, A. C., (1968). Failure of plain concrete under fatigue loading", Review of current knowledge, Ministry of Transport, Road Research Laboratory, RRL Report LR 231.

[20] Demers, C. E., (1998). "Fatigue Strength Degradation of E-glass FRP composites and carbon FRP composites", Construction and Building Materials, V. 12, No. 5, pp. 311-318.

[21] Mallet, G.P., (1991) Fatigue of Reinforced Concrete, State of the Art Review/2, Transport and Road Research Laboratory, HMSO.

[22] Held M. (1992). Ein Beitrag zur Herstellung und Bemessung von Druckgliedern aus hochfestem Normalbeton (B60-B125), Fachbereich konstruktiver Ingeniuerbau Technische Hochschule Darmstadt. Diss. D17, 1992 (in German)

[23] Terrasi G.P. (1998). Mit Kohlenstoffasern vorgespannte Schleuderbetonrohre PhD Thesis, ETH Zurich, Switzerland, Diss. ETH Nr 12454 (in German) 


\begin{tabular}{|c|c|c|c|c|}
\hline No. & Description & $\begin{array}{c}\text { Load Range } \\
\mathbf{Q}(\mathbf{k N})\end{array}$ & $\begin{array}{c}\text { No. of } \\
\text { Cycles }\end{array}$ & $\begin{array}{c}\text { Frequency } \\
\text { (Hz) }\end{array}$ \\
\hline ST1 & Static Test to failure & - & - & - \\
\hline FT1 & Cyclic loading in one direction & +1 to +8 & $2,000,000$ & 5 \\
\hline FT2-1 & Cyclic loading in one direction & +1 to +8 & $1,000,000$ & 5 \\
\hline FT2-2 & $\begin{array}{c}\text { Cyclic loading in one direction } \\
\text { after pole had been rotated by }\end{array}$ & +1 to +8 & $1,000,000$ & 5 \\
\hline FT3 & $\begin{array}{c}\text { Through zero loading: cyclic } \\
\text { loading in two directions }\end{array}$ & -8 to $+8\left(6^{*}\right)$ & $1,000,000$ & 2.5 \\
\hline FT4 & $\begin{array}{c}\text { Through zero loading: cyclic } \\
\text { loading in two directions }\end{array}$ & -8 to +8 & $1,000,000$ & 2.5 \\
\hline
\end{tabular}

*actual value used in experiment due to measurement problems

Table 1 Beam test parameters 


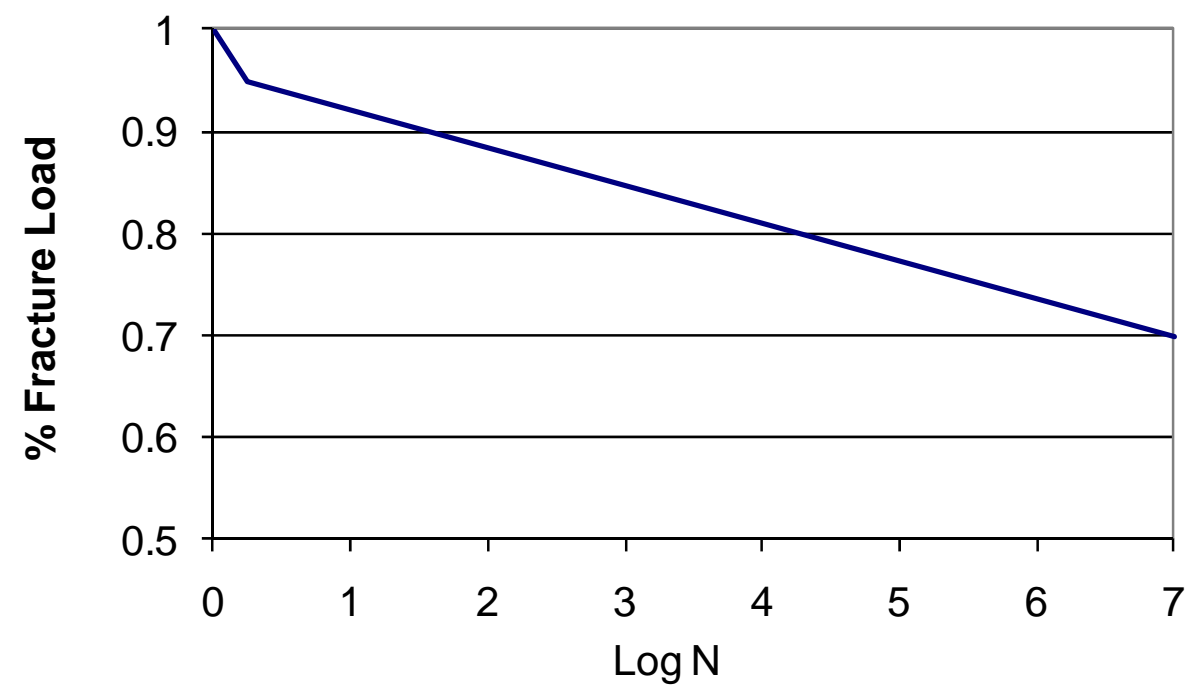

Figure 1. Representative S-N Curve for CFRP tendon for a stress amplitude of 36\% $\sigma_{u}$ 


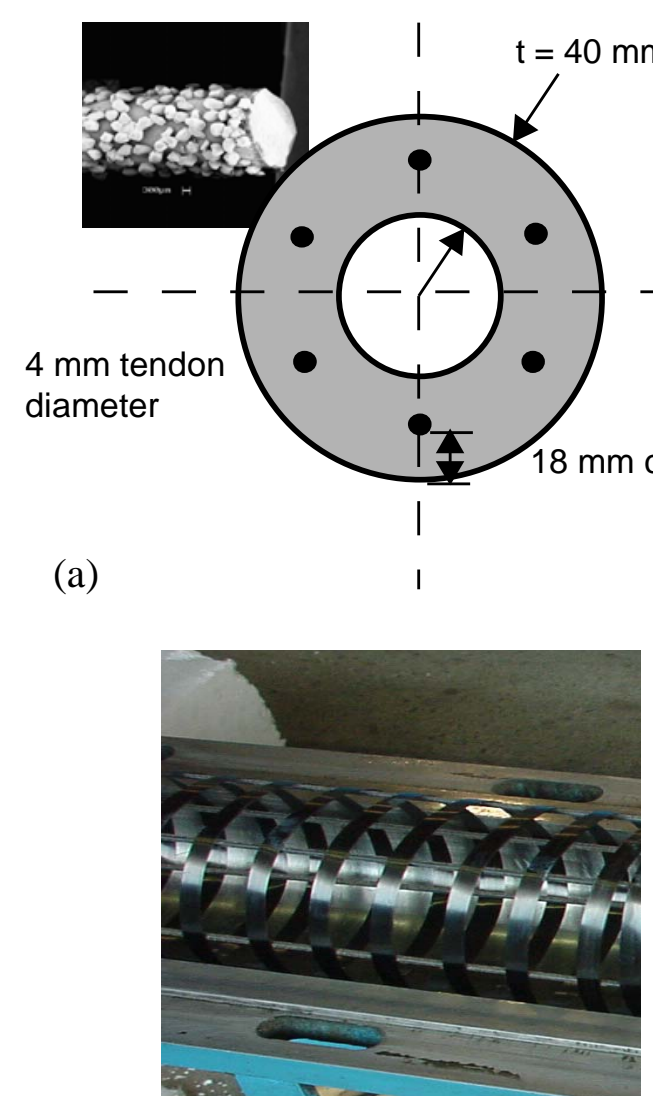

(b)

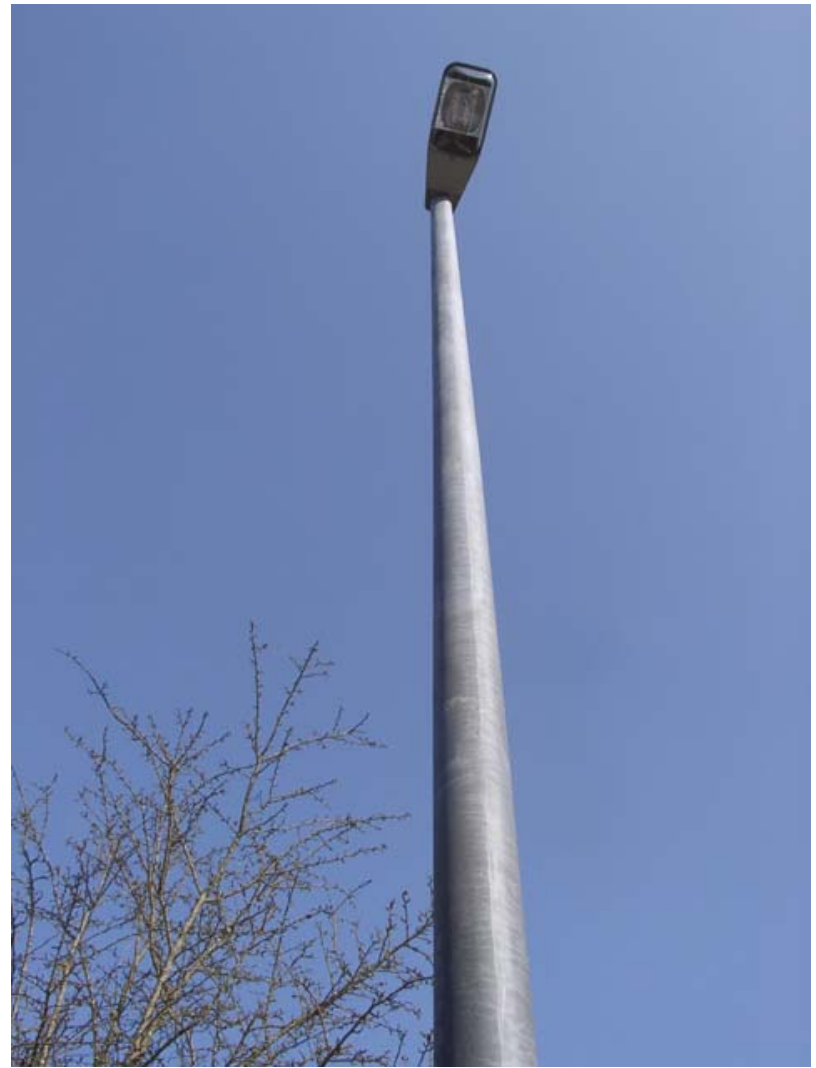

(c)

Figure 2 (a) Cross-section with SEM image of sand-coated tendon (inset) (b) CFRP tape spiral before casting and (c) lighting pole (photo courtesy of SACAC Ltd) 


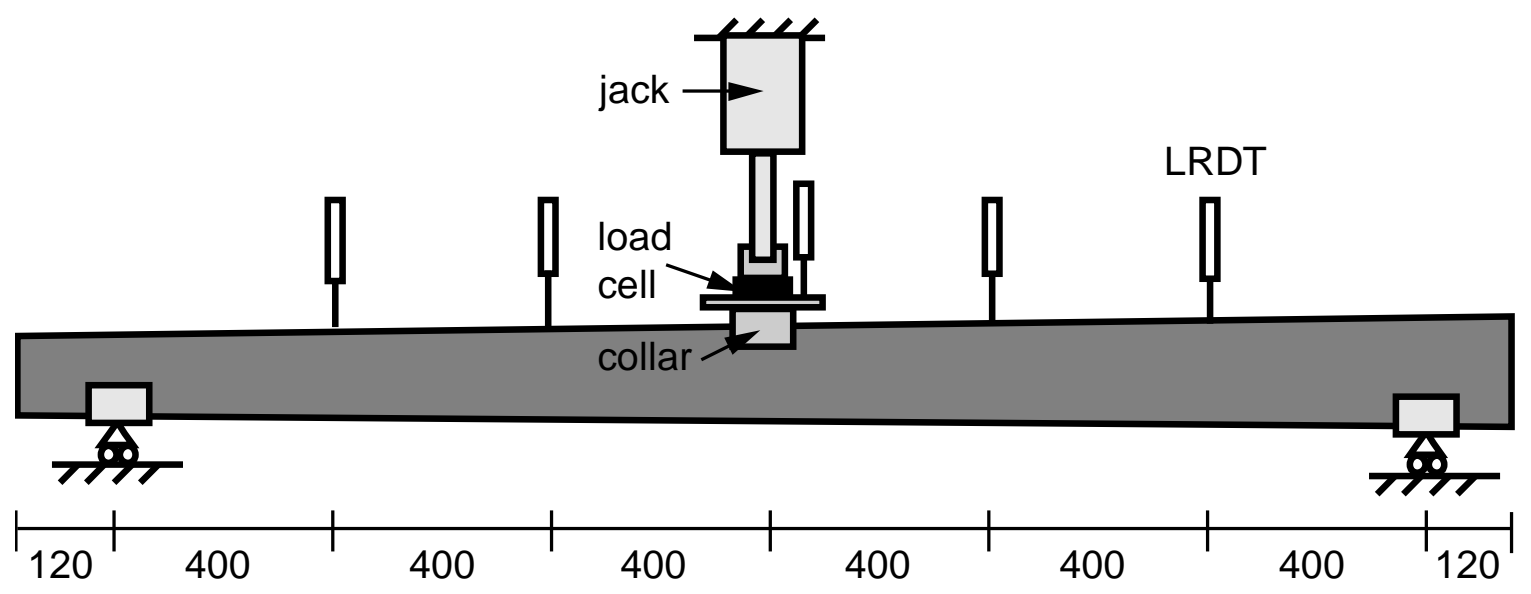

Figure 3 Schematic diagram of fatigue test rig for downwards loading (dimensions in $\mathrm{mm}$ ) 


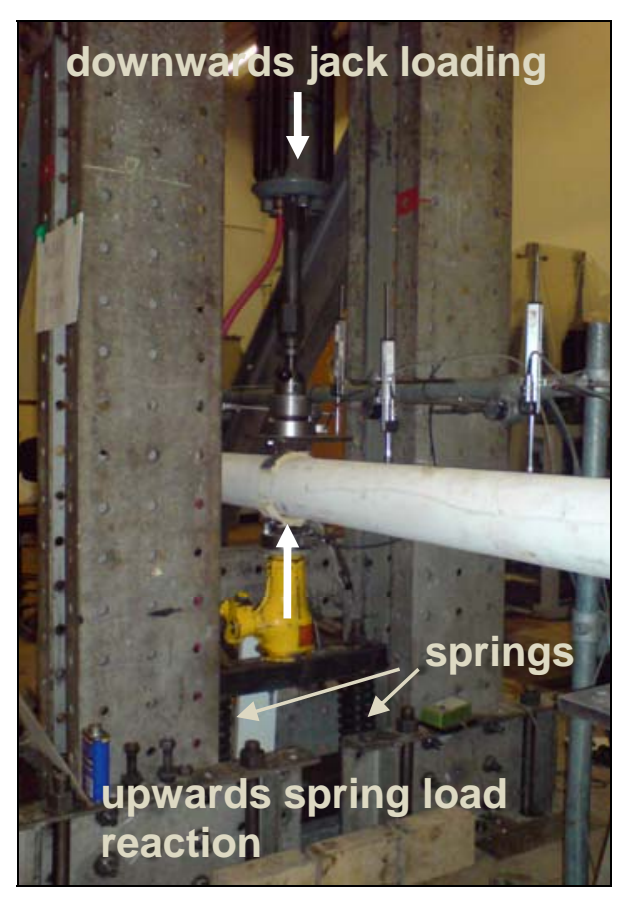

(a)

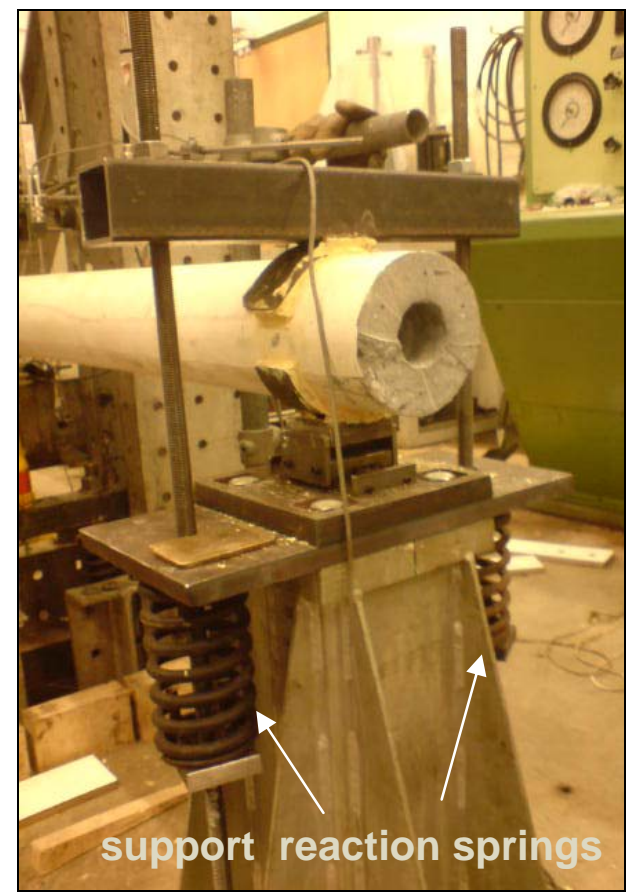

(b)

Figure 4

Load reversal test set-up (a) modified loading jack and (b) modified support 


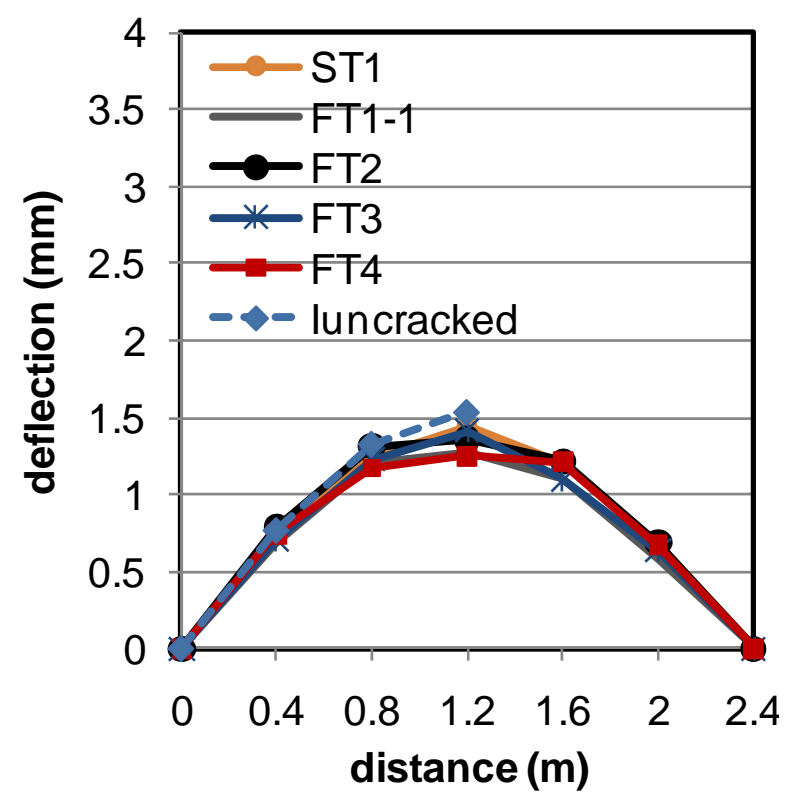

(a)

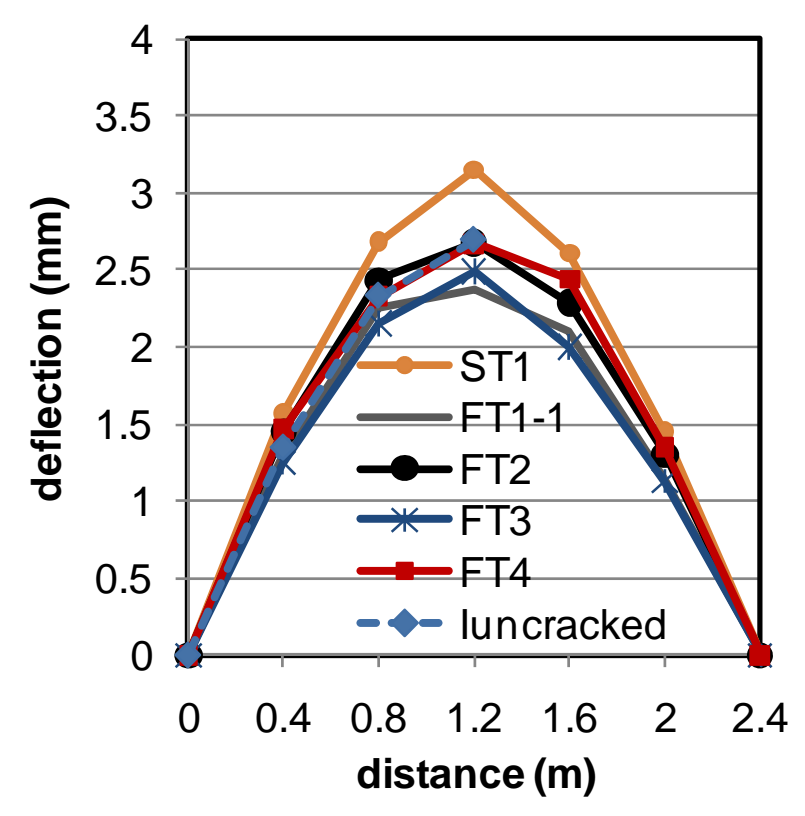

(b)

Figure 5 Deflection profile along length of pole during first static load cycle at (a) 4 $\mathrm{kN}$ and (b) $7 \mathrm{kN}$ 


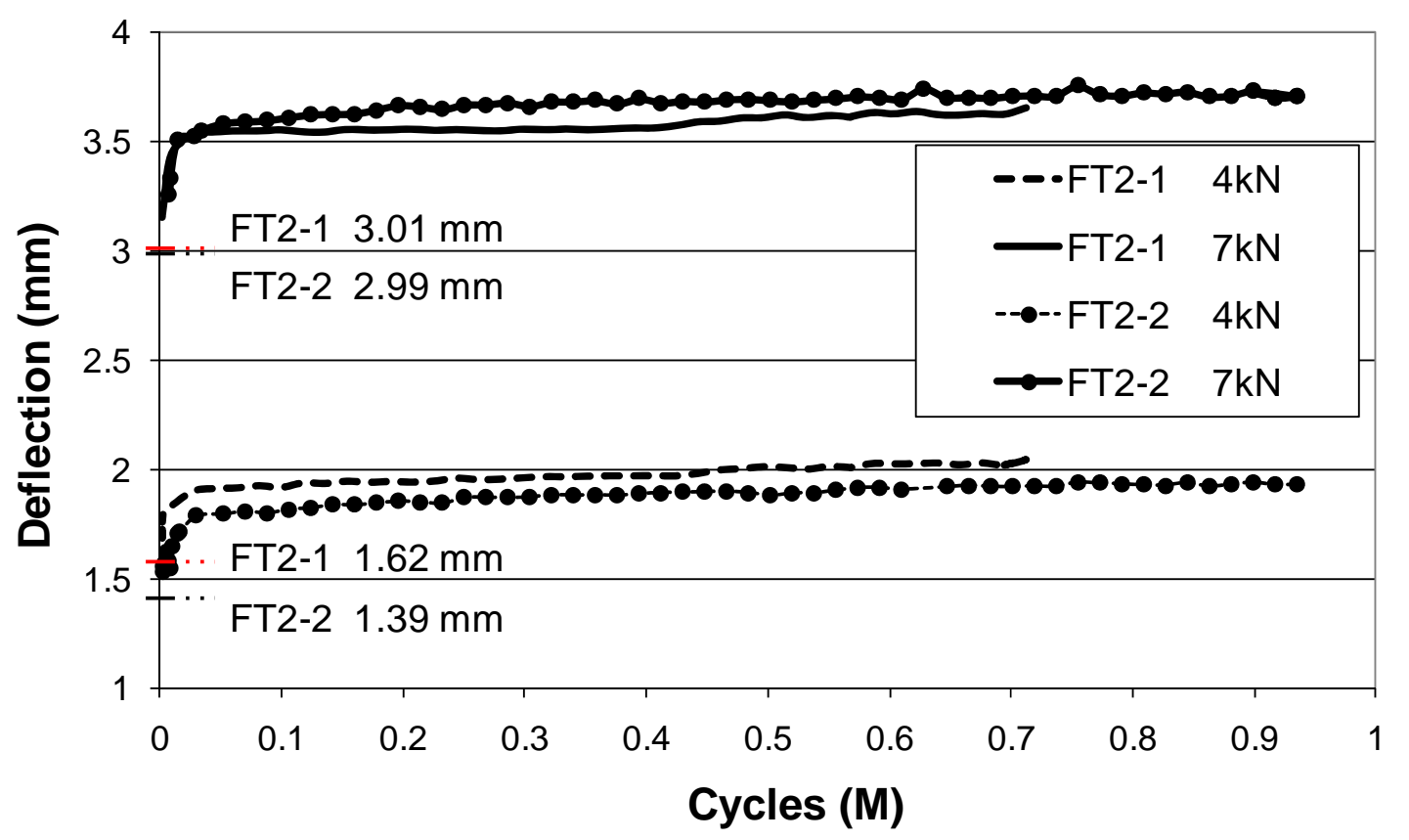

(a)

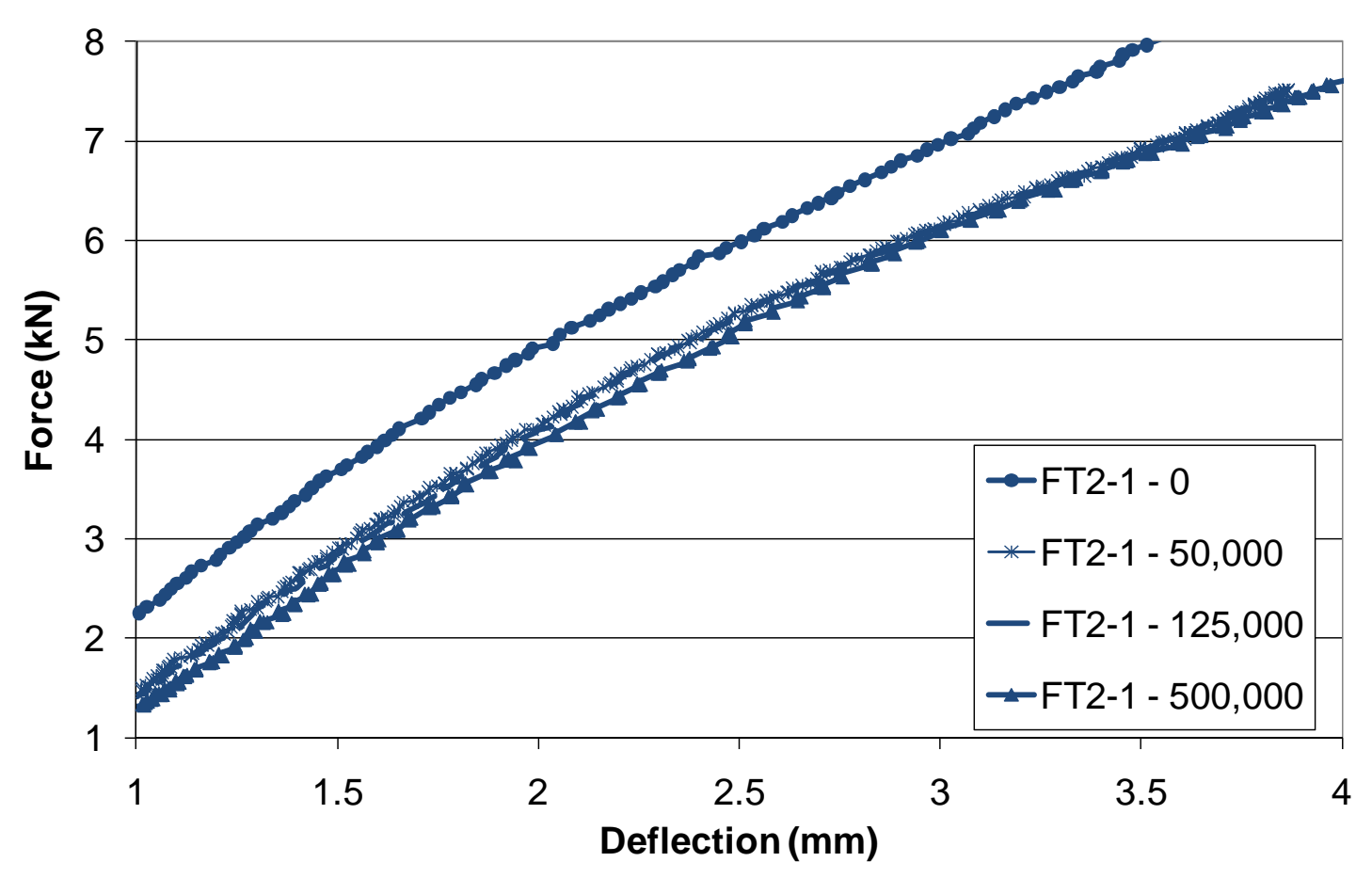

(b)

Figure 6 Dynamic deflection plots for (a) FT2-1 and FT2-2 with increasing cycles at loads of 4 and $7 \mathrm{kN}$ and (b) FT2-1 at selected numbers of cycles 


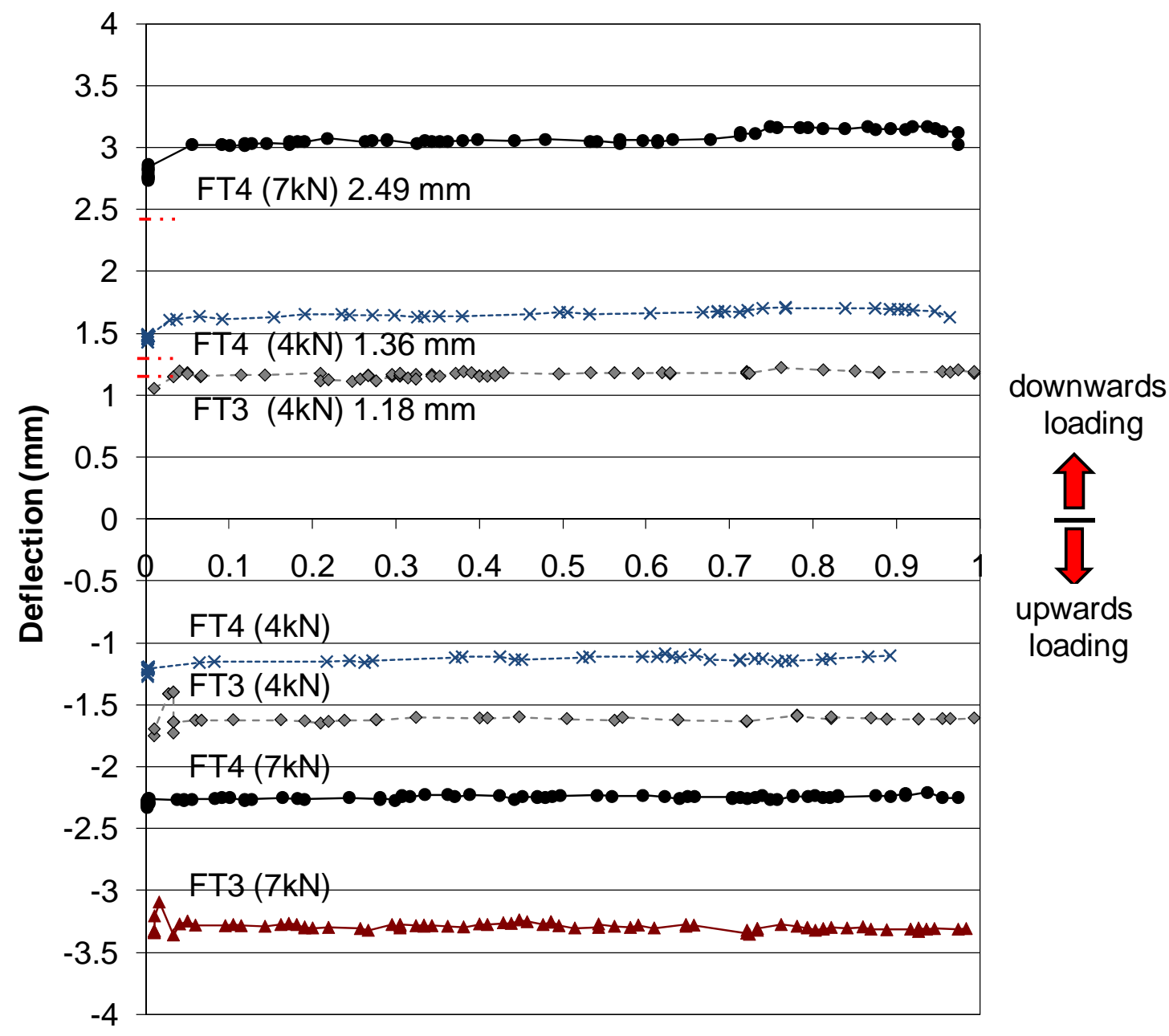

\section{Cycles (M)}

Figure $7 \quad$ Dynamic deflection plots for FT3 and FT4 with increasing cycles showing upwards and downwards displacement trends at loads of $4 \mathrm{kN}$ and $7 \mathrm{kN}$ 


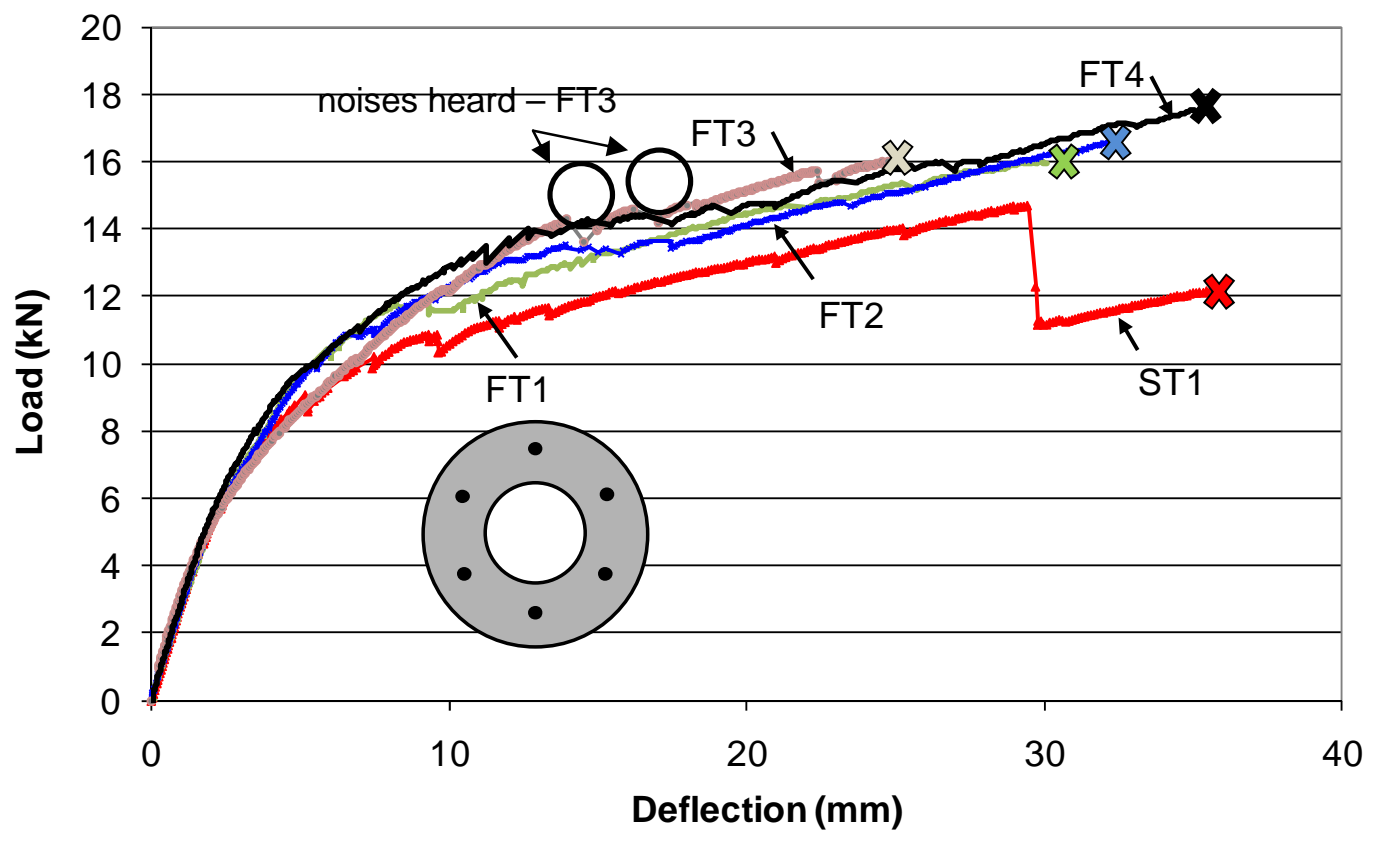

Figure 8 Static failure load-deflection plots 


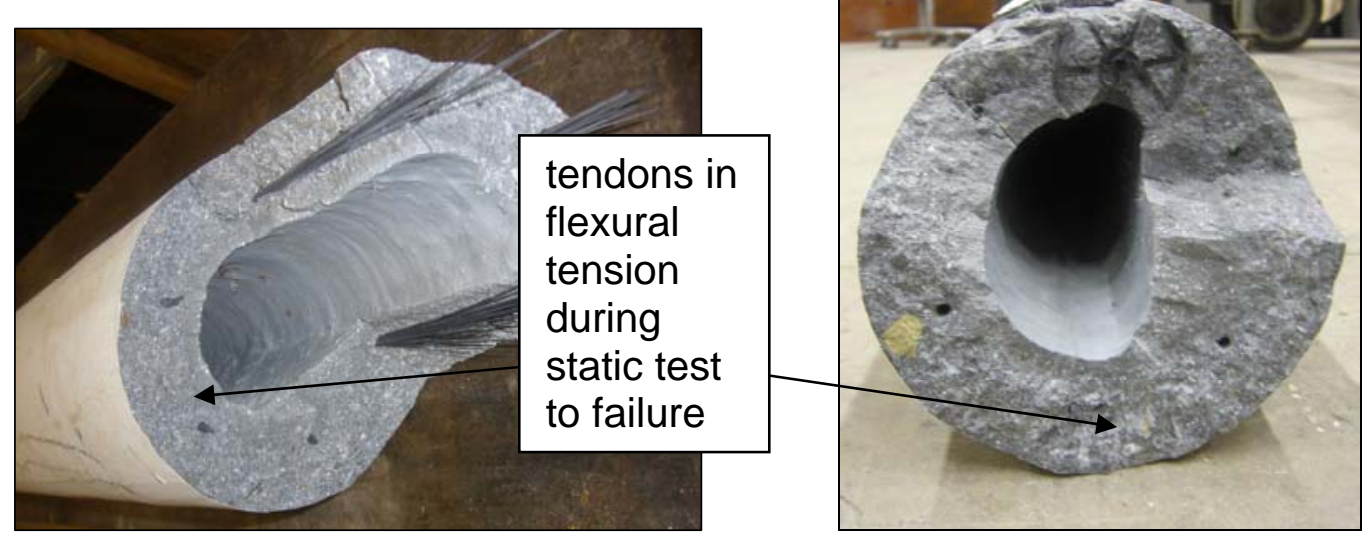

(a)

(b)

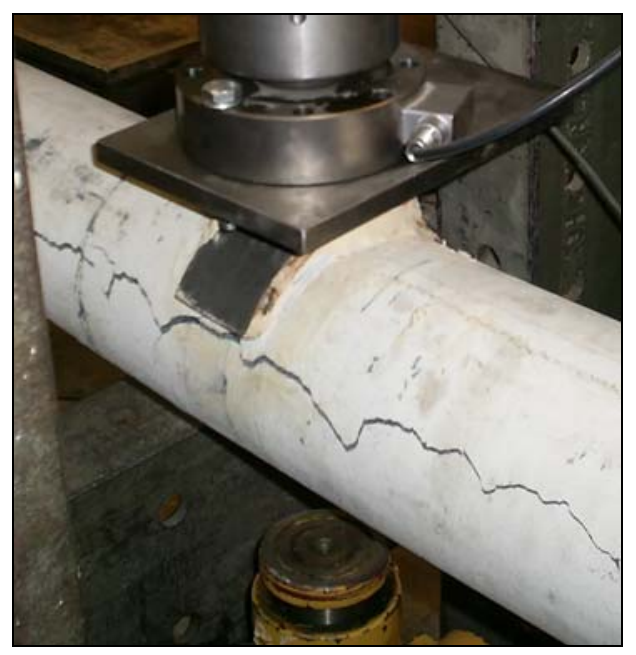

(c)

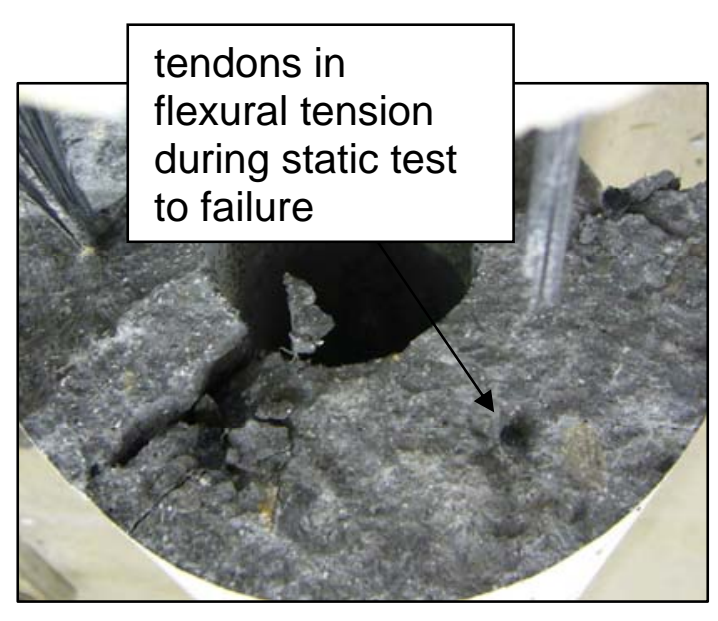

(d)

Figure $9 \quad$ Failure of (a) FT1 (b) FT2 (c) FT4 and (d) FT3 

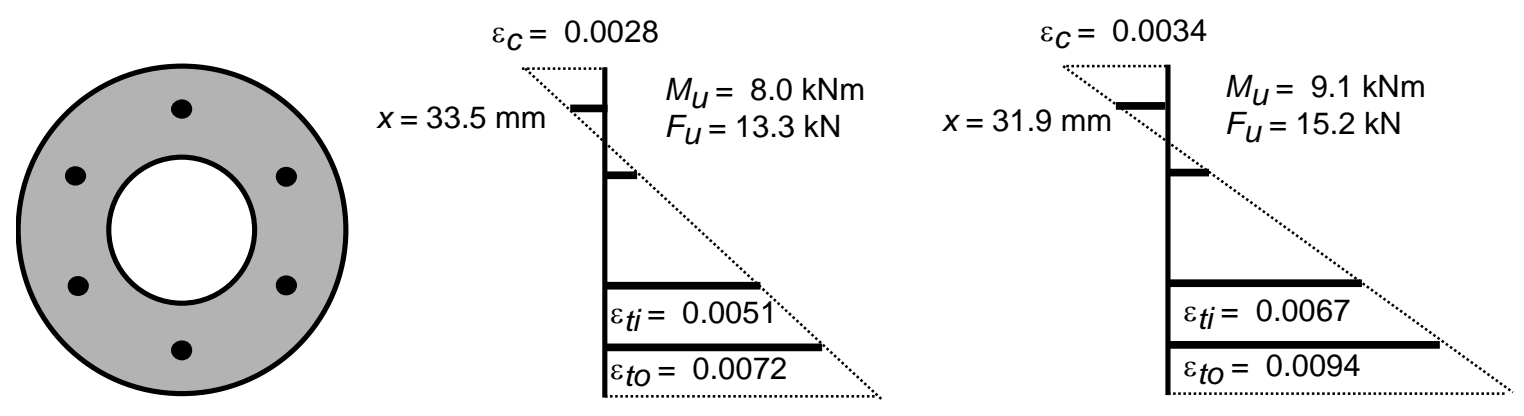

(a)

(b)
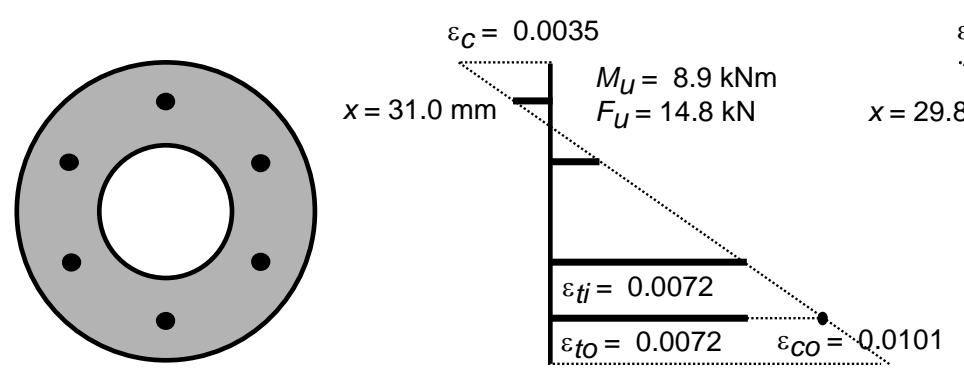

(c)

(d)

Figure 10 Comparison of curvature diagrams investigating changes in material properties and debonding assuming (a) baseline case (b) the tendons are 15\% stronger than the manufacturer's data (c) tendon debonding and (d) tendon debonding and a 15\% increase in tendon capacity 